\title{
APA YANG HARUS KITA LAKUKAN PADA KASUS BULLYING ? IMPLIKASINYA TERHADAP MANAJEMEN BIMBINGAN DAN KONSELING DI SEKOLAH
}

\author{
Anaway I Mansyur', Herdi Herdi ${ }^{2}$ \\ Email:wayirianti@gmail.com ${ }^{1}$ \\ Pasca Sarjana Bimbingan dan Konseling, Universitas Negeri Jakarta ${ }^{1}$ \\ Prodi Bimbingan dan Konseling, Universitas Negeri Jakarta ${ }^{2}$
}

\begin{abstract}
Teenagers who are victims of bullying are more at risk of experiencing various health problems, both physically and mentally. The problems that are more likely to be suffered by children who are victims of bullying, among others, the emergence of various mental problems such as depression, anxiety and sleep problems that may be carried into adulthood, physical health complaints, such as headaches, abdominal pain and muscle tension, a sense of not safe while in the school environment, and decreased learning enthusiasm and academic achievement. In fairly rare cases, children who are victims of bullying may show violence. Coloroso (2007) states that victims of bullying are usually new children in an environment, the youngest child in school, usually a smaller child, fearful, perhaps unprotected, a child who has experienced trauma or has been hurt before and is usually very sensitive, avoiding peers to avoid more severe pain, and find it difficult to ask for help. This article aims to find out about counseling service management in nine countries in overcoming the problem of bullying, and the factors that cause bullying. The data source of this paper is done by the documentation study method. In this article the results show that the factors that influence the occurrence of bullying can come from individuals, families, play groups, to the community environment of the perpetrators. This action is closely related to the world of social work, which in this case is required to be a counselor for bullying perpetrators.
\end{abstract}

Keywords: Bullying; Counseling Service Management

\section{PENDAHULUAN}

Herbert (Lee, 2004) mendefinisikan bullying sebagai sesuatu yang mengerikan dan kejam yang dilakukan oleh seseorang kepada anak atau sekelompok anak. Penindasan dapat terjadi sekali atau berulang kali. Para korban bullying akan merasa malu, sakit atau terhina dan terancam. Para pelaku bullying mungkin tidak menyadarinya. Penindasan dapat didefinisikan sebagai tindakan agresif atau perilaku yang disengaja, dilakukan oleh sekelompok orang atau seseorang berulang kali dan dari waktu ke waktu kepada korban yang tidak dapat membela diri dengan mudah (Olweus in (Geldard, 2012).
Penekanan pada tindakan negatif membuat penindasan berkonotasi tindakan yang disengaja untuk memberi orang lain perasaan tidak nyaman.Menghukum, merendahkan, mencela, memberi nama panggilan, menendang mendorong untuk memukul meminta uang (merebut, memeras), menghindari, menolak menjadi teman adalah bentuk nyata dari bullying Perilaku yang lebih populer di kalangan remaja saat ini adalah untuk mendiskreditkan siswa baru atau teman sekelasnya.

Konsep Djuwita (2006) bullying digolongkan sebagai perilaku yang tidak baik atau perilaku menyimpang, ini karena perilaku tersebut memiliki dampak yang 
serius. Berdasarkan O'Moore (2012) Penindasan cyber perlu dihadapi di Irlandia Penelitian ini menunjukkan satu dari lima siswa ditemukan terlibat baik sebagai penindas cyber, dan juga korban cyber mencerminkan bahwa penindasan cyber adalah penyebab masalah dari perhatian besar kepada siswa, orang tua dan guru.

Di Inggris, proses pelaporan bullying lebih kompleks daripada yang diperkirakan orang dewasa (O'Brien, Munn-Giddings, \& Moules, 2018). Siswa harus menegosiasikan web yang rumit dalam memutuskan terlebih dahulu apakah bullying cukup serius untuk dilaporkan. Konsep bullying 'serius' adalah perdebatan, terutama antara asrama dan siswa harian, tetapi kekerasan fisik dan / atau pengulangan cenderung menjadi karakteristik bullying 'serius'.

Indonesia menjadi tempat pertama dalam penelitian yang dilakukan oleh LSM Plan International dan Pusat Internasional untuk Penelitian tentang Perempuan (IRCW) terkait dengan bullying, penelitian ini dilakukan di beberapa negara di kawasan Asia. Sebanyak $84 \%$ anak-anak di Indonesia mengalami bullying di sekolah, sekitar 9.000 anak terlibat dalam penelitian ini yang berusia 12-17 tahun (Arofa, Hudaniah, \& Zulfiana, 2018).
Di Indonesia, kita mengenal Taman Kanak-kanak (TK), Sekolah Dasar (SD), Sekolah Menengah (SMA), dan Pendidikan Tinggi. Dalam strata pendidikan, kami ingin menyesuaikan kemampuan yang kami miliki dengan pelajaran yang akan kami pelajari. Namun, kadang-kadang, di hadapan strata seperti ini atau pendidikan tingkat pengelompokan, khususnya pendidikan tertentu akan melahirkan senioritas. Hal ini dianggap sebagai media untuk menunjukkan bahwa strata tertinggi sebagai kelompok paling kuat dan kuat.

Akibatnya, banyak tindakan yang tidak pantas kemudian terjadi. Seperti, kekerasan atau apa yang disebut sebagai bullying bahkan hingga pelecehan seksual. Tentu ini kejadian buruk bagi pendidikan Indonesia. Peristiwa seperti ini, tidak hanya satu atau dua kali, tetapi berkalikali dan tidak hanya di tingkat Perguruan Tinggi saja, tetapi sudah menyebar tingkat yang lebih rendah misalnya, Sekolah Dasar (Anis, 2012). Jika dilihat dari perspektif hukum, hal-hal seperti itu adalah kejahatan yang terkandung dalam Hukum Pidana (KUHP). Penelitian tentang bullying telah dilakukan, yang salah satunya adalah Christhoponus Argo Widiharto et al. (2001: 56) dalam hasil penelitiannya tentang perilaku bullying dalam hal harga diri dan pemahaman 
moralitas anak-anak, menunjukkan bahwa ada hubungan negatif antara harga diri, pemahaman moral dan perilaku bullying. Sedangkan untuk harga diri dan pemahaman moral berkontribusi 23,1\% terhadap perilaku bullying.

Berdasarkan hubungan dengan tema tersebut pemahaman peneliti tentang bullying masih sangat rendah baik dari pelaku bullying maupun korban bullying sehingga peneliti ingin meningkatkan pemahaman bullying di kalangan siswa. Manajemen konseling adalah kegiatan yang memfasilitasi dan melengkapi fungsi staf konseling (Gibson \& Mitchell, 2011). Sehingga manajemen bimbingan dan konseling dimulai dari perencanaan, pengorganisasian hingga evaluasi untuk mencapai tujuan. Untuk alasan ini, penelitian ini berfokus pada peninjauan hasil penelitian terkait dengan bimbingan dan manajemen bimbingan untuk membantu meminimalkan bullying pada siswa.

\section{METODE PENELITIAN}

\section{Sumber Data dan Strategi Pencarian}

Batasan pada istilah pencarian studi literatur dalam kategori aspek akademik pribadi dipilih melalui konsep pembelajaran atau motivasi akademik, keterlibatan akademik, dan regulasi diri. Ketiganya merupakan bagian dari penentu prestasi akademik remaja berdasarkan
Schunk, Pintrich, dan Meece (2012) yang diduga memiliki kaitan dengan kecanduan smartphone.

Strategi pencarian adalah melalui pencarian alat penelitian Pencarian Terpadu dari Taylor \& Francis Group. Database pemilihan literatur dalam penelitian ini yaitu Taylor \& Francis, Sage Journals and Science Direct. Pencarian dilakukan dari 05 Juli hingga 11 Juli 2019. Proses pemilihan studi dihilangkan dan dipelajari termasuk dalam analisis tindak lanjut terdiri dari penyaringan, membaca, dan mengidentifikasi judul atau abstrak studi dari kedua database.

Kata kunci pencarian dalam database Taylor \& Francis, Sage Journals and Science Direct adalah: (a) ('Bullying' DAN 'konseling dan bimbingan' DAN DAN 'penanganan bullying' DAN 'manajemen konseling dan bimbingan'). Dari proses pertama (a), peneliti menemukan 67 studi ilmiah sebelum pemilihan lanjutan terkait dengan kata kunci. Dari proses kedua (b), peneliti hanya menemukan 36 studi yang terkait dengan kata kunci.

Pencarian studi pada basis data menggunakan batasan periode publikasi dan penelitian antara 1985 dan 2019. Para peneliti juga memfilter data pencarian hanya untuk artikel-artikel penelitian ilmiah yang telah melalui proses peer 
review. Berdasarkan total, studi yang dipilih untuk studi lebih lanjut hanya terdiri dari 10 studi, 8 dari manajemen konseling dan bimbingan, 2 dari bullying.

Berdasarkan pencarian basis data pertama, jumlah penelitian yang dipilih adalah 3 penelitian yaitu penelitian kualitatif. Pada database kedua, studi yang dipilih hanya berjumlah 10 studi. Seleksi ini didasarkan pada eliminasi studi yang berada di luar konteks studi manajemen pencarian, konseling dan bimbingan. Dalam pencarian studi, peneliti menemukan beberapa studi memiliki judul yang sama meskipun melalui kata kunci yang berbeda.

Untuk mencegah duplikasi, studi berjudul yang sama diputuskan untuk diakumulasikan dengan proses pencarian pertama. Kemudian, penelitian ini diputuskan hanya pada jumlah studi kata kunci pertama. Data proses pemilihan terdiri dari: (1) identifikasi judul, nama peneliti, dan abstrak; (2) menyaring artikel penelitian, terutama dalam tujuan penelitian, metode dan hasil; (3) penilaian apakah studi ini dipilih dalam analisis atau dihilangkan; dan (4) memberikan keputusan studi yang dipilih atau dihilangkan.

Dari total 67 studi dari pencarian basis data pertama, 36 studi dianggap memasuki fase penilaian dan hanya studi yang dipilih. Dalam database kedua, total penelitian yang dipertimbangkan dipilih hanya 10 studi. Berdasarkan hal itu, total studi studi lebih lanjut dalam penelitian ini adalah 7 studi, di bagian "Hasil dan Diskusi" menunjukkan aliran diagram fase pemilihan studi pada dua database.

Mengacu pada studi kualitatif yang mirip dengan ringkasan meta, penelitian ini menerapkan tahapan analisis dari Tromp, Zwaan, dan Van De Vathorst (2016). Tahap pertama adalah ekstraksi hasil studi yang terkait dengan konsep utama. Tahap kedua yaitu membuat daftar hasil dari setiap studi yang dipilih agar sesuai dengan kategori faktor. Tahap ketiga, mengelompokkan efek kecanduan sesuai dengan kategori dan presentasi dalam bentuk terintegrasi. Prosedur yang dilakukan adalah melalui pembacaan literasi yang dipilih dengan cermat, teliti, dan mandiri. Peneliti menggaris bawahi unsur-unsur penting untuk setiap studi.

\section{Managemen Bimbingan dan Konseling}

Dari hasil seleksi artikel sejak 1983, dunia pendidikan sudah mulai berkonsentrasi dengan bimbingan dan konseling. Ini juga memengaruhi pola pikir negara-negara tetangga dalam mengembangkan bimbingan dan konseling. Perspektif posisi bimbingan dan konseling telah mempengaruhi sekolah menengah di Inggris dalam 
percakapan terakhir. Tingkat primer dihilangkan dari diskusi karena hanya baru-baru ini harus diambil di Inggris untuk digunakan dalam bidang ini (Sisterson, 1983).

Sepuluh tahun terakhir tidak dapat didiskusikan tanpa mengacu pada perkembangan sebelumnya. Dengan demikian juga membuat nyaman untuk periode beberapa tahun, di mana gerakan baru meruapakan kesempatan untuk mengkonsolidasikan dan mengembangkan status di mana hak untuk kebaruan dan antusiasme yang memulai segalanya (Hughes, 1985). Konseling telah disetujui oleh pembuat kebijakan pemerintah sebagai model yang baik dalam memberikan bimbingan konseling di sektor pasca-primer sejak UndangUndang Pendidikan 1998 (DES, 2005a, 2009, 2012).

Untuk memberikan panduan yang diperlukan bagi sekolah di mana nantinya diharapkan untuk bersama-sama mengembangkan rencana bimbingan untuk mendukung kebutuhan siswa mereka. Bimbingan yang diberikan bisa berupa Bimbingan Kelompok untuk mencegah terjadinya bullying pada diri siswa dan Konseling Individu bila telah terjadi kasus bullying pada siswa. Konseling Indivu membantu siswa menghadapi masalah yang terjadi pada diri siswa.

Peran guru reguler di seluruh sekolah yang menyetujui konseling hanya mendapat sedikit perhatian dalam sistem pendidikan atau dalam penelitian empiris. Artikel ini membahas defisit melalui pembahasan studi kasus yang dilakukan di satu sekolah pada tahun 2012. Hal ini memposisikan temuan-temuan studi dalam konteks yang membahas evaluasi ulang pasca-ketentuan penyediaan konseling dalam APBN 2012 yang telah disetujui secara substansial terakhir (Hearne \& Galvin, 2015).Perlu Pemberian Konseling yang tertuang dalam APBN dan merealisasikan konseling tersebut pada sekolah-sekolah, khususnya sekolah yang banyak terjadi bullying di dalamnya. Dari beberapa penelitian sebelumnya terkait bimbingan dan konseling menunjukkan adanya perkembangan yang baik di setiap sekolah.

Di negara Newfoundland dan Labrador, insiden tertentu intimidasi verbal-relasional yang juga menarik adalah bimbingan dari konseling dan pelatihan dalam program intimidasi dan perilaku pendukung yang positif.

Bimbingan konseling cenderung mengambil berbagai tanggung jawab dalam menangani intimidasi verbal- 
relasional dan cenderung meminta dukungan dari orang dewasa lainnya. Managament bimbingan dan konseling berperan untuk memasukan didalam kegiatan layanan bimbingan klasikan, bimbingan kelompok dan konseling individual untuk mengantisipasi bullying yang terjadi pada siswa-siswa di sekolah. Dikatakan bahwa bimbingan konseling berperan penting dalam mengatasi intimidasi dan pelatihan sekolah dalam bidang ini sangat penting untuk bimbingan konseling.

Implikasi penelitian dan arah penelitian masa depan dibahas (PowerElliott \& Harris, 2012). Sehingga penelitian ini menunjukkan bahwa peran dari bimbingan dan konseling dapat mengatasi perilaku bullying di sekolah. Fenomenografi sebagai pendekatan kualitatif yang layak dalam penelitian bimbingan dan konseling.

Peta studi fenomenografi adalah cara yang berbeda secara kualitatif di mana orang mengalami fenomena spesifik dan membantu peneliti untuk menggambarkan aspek yang dibuat dalam satu cara untuk mengalami fenomena tertentu yang secara kualitatif berbeda dari studi praktisi karir lain yang disebutkan di atas dalam konsep kompetensi untuk media sosial di tinjauan sejawat Internasional dan nasional dari konferensi pengembangan karir, menerima tanggapan yang menawarkan bukti validitas komunikatif.

Dalam ulasannya tentang penelitian fenomenografi, Tight (2016) menyimpulkan bahwa desain penelitian ini secara signifikan meningkatkan penelitian pendidikan, dan penggunaannya dapat diperluas ke bidang lain. Fenomenografi kontribusi potensial untuk penelitian dan praktik bimbingan dan konseling terletak pada kemampuannya untuk menjelaskan perbedaan dan perubahan makna yang diungkapkan oleh orang-orang tentang fenomena.

Sebagai contoh, pengetahuan tentang variasi dalam bimbingan atau konseling praktisi karir atau pengalaman individu warga negara dapat menawarkan informasi berharga dan memiliki dampak penting pada praktik, teori dan pelatihan di lapangan. Sampai saat ini, ada beberapa studi fenomenografi di bidang bimbingan dan konseling, tetapi kami mendorong para sarjana untuk mempertimbangkan kemungkinan pendekatan fenomenografis dalam penelitian masa depan mereka (Kettunen \& Tynjälä, 2018). Faktor-faktor yang mempengaruhi keterlibatan sekolah menengah guru reguler dalam pendekatan seluruh sekolah untuk bimbingan dan konseling adalah wawancara dengan 12 guru sekolah menengah di Hong Kong. 
Penelitian Dalam Bimbingan dan Konseling

Tema-tema yang muncul termasuk kepemilikan guru atas peran mereka dalam bimbingan dan konseling siswa, penyelarasan disposisi mereka dengan kebijakan pendidikan, misi dan budaya sekolah, dan filosofi mereka dalam pendidikan. Temuan tentang apa yang sebenarnya dilakukan para guru ini adalah bimbingan dan konseling. Implikasi bagi pembuat kebijakan, administrator dan pemimpin untuk program bimbingan dan konseling komprehensif yang diambil dari kendala yang membatasi potensi penuh orang yang diwawancarai dalam membantu siswa (Lam \& Hui, 2010) layanan konseling dan konseling sekolah (SGC) di sekolah menengah Zimbabwe sebagaimana dirasakan oleh siswa. dan konselor sekolah.

Studi ini adalah bagian dari studi yang lebih besar tentang penilaian efektivitas layanan bimbingan dan bimbingan sekolah di sekolah menengah Zimbabwe. Desain survei digunakan dalam penelitian ini. Sampel terdiri dari 950 peserta di mana tiga ratus empat belas (165 pria dan 149) wanita adalah penasihat sekolah sementara, 636 (314 pria dan 322 wanita) adalah siswa.

Hasil Penelitian Studi Management Bimbingan dan Konseling
Studi ini menemukan bahwa penasihat sekolah dan siswa percaya bahwa layanan ini menghasilkan manfaat pribadi-sosial, karier dan kejuruan. Secara keseluruhan, keduanya adalah penasihat sekolah dan siswa menilai layanan SGC Zimbabwe secara adil (Chireshe, 2017). Pendapat siswa tentang kecukupan layanan bimbingan dan konseling tidak menunjukkan perbedaan yang signifikan menurut jumlah saudara kandung. Siswa yang memiliki saudara kandung menilai layanan konseling lebih positif daripada mereka yang tidak memiliki saudara kandung.

Dalam studi penelitian ini, pendapat siswa tentang kecukupan konsultasi psikologis dan layanan bimbingan tidak menunjukkan perbedaan yang signifikan ketika status orang tua dipertimbangkan. Meskipun siswa yang orang tuanya berpisah, bercerai atau yang ibu atau ayahnya telah meninggal, memerlukan layanan konsultasi psikologis lebih lanjut, status orang tua bukan merupakan faktor yang efektif dalam layanan bimbingan.

Dalam studi ini, hubungan antara pendapat siswa tentang konsultasi psikologis dan layanan bimbingan dan apakah siswa tahu konsuler mereka mengungkapkan bahwa secara statistik, ada perbedaan yang signifikan. 
Menurut hasil penelitian, persepsi siswa yang mengetahui konseling mereka tentang kecukupan layanan bimbingan lebih tinggi daripada siswa yang tidak mengenal konseling. Oleh karena itu, konseling harus mengatur kegiatan untuk mendorong fungsi konselor di sekolah dan meningkatkan efisiensi secara positif. Studi ini menunjukkan pendapat siswa tentang kecukupan konsultasi psikologis dan layanan bimbingan belum menunjukkan perbedaan yang signifikan berdasarkan apakah mereka menerima layanan sebelumnya atau tidak?

Temuan ini mendukung item pada skala, keberadaan konselor di sekolah membuat saya merasa lebih baik" dengan menerima poin tertinggi. Oleh karena itu, meskipun siswa tidak berdiskusi secara langsung dengan konselor di sekolah, keberadaan guru membantu mereka merasa lebih baik.Hal ini sekali lagi menunjukkan bahwa konsultasi layanan di sekolah adalah penting.

Dalam pembelajaran, pendapat siswa tentang kecukupan konseling psikologis dan layanan konseling dan apakah orang tua hanya berdiskusi dengan konselor di sekolah direduksi menjadi signifikansi statistik (Özmen, Eren, \& Tezer, 2016).

Studi ini menyoroti survei masalah berikut ini (a) ketersediaan bimbingan dan konseling pelajaran di Sekolah Afrika; (b) ketersediaan layanan bimbingan dan konseling bagi siswa; (C) jika siswa mengetahui layanan bimbingan dan konseling yang disediakan di sekolah mereka; dan (d) kesulitan dan tantangan yang dihadapi oleh konselor dalam menerapkan program bimbingan dan konseling di sekolah mereka.

Peserta mengemukakan kesulitan yang meliputi kekurangan konselor yang memenuhi persyaratan dan kekurangan staf yang dihadapi di sekolah yang disurvei. Ini bisa menjadi salah satu faktor yang berkontribusi mengapa program konseling dan konseling masih tidak memadai dan tidak dianggap serius di sekolah hitam.

Meskipun bimbingan adalah subjek yang tidak dapat diuji, kepentingannya tidak dapat terlalu ditekankan karena kehidupan dan karier sekolah siswa sering menjadi terdistorsi dengan banyak faktor, termasuk penyalahgunaan zat, pelecehan emosional baik di rumah maupun di sekolah, disfungsi keluarga, perceraian, remaja kehamilan, HIV / AIDS, beberapa di antaranya datang dengan kekacauan emosional.

Dengan program bimbingan dan konseling yang tersedia, siswa dapat belajar mengatasi distorsi ini. Penelitian saat ini menunjukkan bahwa bimbingan 
dan konseling sangat membantu siswa dalam upaya mereka untuk menghindari tertular HIV / AIDS, penyalahgunaan obat dan kehamilan yang tidak diinginkan (Glasser, 1998; Pemerintah Gazzette No. 22512, 2001; Mutemi, 2006). Untuk mengatasi masalah di atas management bimbingan dan konseling perlu bekerja sama dengan stakeholder dalam hal ini pemerintah perlu mempekerjakan kembali konselor terlatih dan mengalokasikan lebih banyak sumber daya untuk melatih konselor yang dapat memberikan layanan ke sekolah hitam.

Dengan demikian, cenderung meningkatkan kualitas program bimbingan dan konseling dalam hal ini sekolah (Muribwathoho \& Shumba, 2006). Ruang konseling dianggap oleh sebagian besar klien yang disebut sebagai tempat untuk melarikan diri dari tuntutan pendidikan. Sebaliknya, mereka yang tidak terlibat dalam konseling menganggapnya hanya untuk siswa yang memiliki masalah, dan cenderung takut dikaitkan dengan layanan karena stigma yang dihasilkan. Klien yang dirujuk sendiri ditunjukkan lampiran untuk layanan dan kepemilikan.

Nilai-nilai dan pembentukan sikap peserta yang berbeda didasarkan pada tiga istilah, meringkas nilai, pendapat, dan perilaku: 'pandangan dunia' (Ivey,
D'Andrea, Ivey, \& Simek-Morgan, 2007), 'kognisi' (Bodenhausen, Macrae, \& Hugenberg, 2003) dan 'Skema budaya' (Ridley, Mendoza, Kanitz, Angermeier, \& Zenk, 1994).

Pembentukan pandangan dunia peserta, proses skema kognisi dan konseling budaya didahului oleh pengetahuan dan informasi yang diperoleh dari pengalaman mereka di lingkungan mereka, terutama sistem sekolah. Citra yang dirasakan dan konseling perawatan adalah standar evaluasi bagi mereka untuk membentuk sikap positif atau negatif terhadap layanan. Elemen-elemen ini dapat menjelaskan sikap selektif mereka ketika mereka lebih suka platform yang berbeda dari konseling yang mereka alami sebagai kurang mengancam. Studi ini menekankan pentingnya memahami bimbingan dan konseling layanan dalam proses pemahaman, pengakuan dan negosiasi sistemik antara siswa dan sistem sekolah.

Melihat sikap siswa dari perspektif non esensialis memfasilitasi makna yang relevan secara budaya, memberikan makna yang lebih besar pada manfaat memahami perbedaan dalam perilaku dan sikap di kalangan siswa (Mohd Daud \& Bond, 2013).

Status terkini dari konseling berbasis sekolah dan layanan psikologis 
untuk anak-anak sekolah dan keluarga mereka di Macau. Mengadopsi model eko-sistemik, beberapa artikel terbaru tentang konseling berbasis sekolah dan layanan psikologis di negara-negara Asia Tenggara ditinjau, dan data serupa dari individu yang saat ini menyediakan layanan seperti itu di Macao diperiksa.

Temuan menunjukkan bahwa ada kebutuhan besar untuk layanan psikologis, terutama yang berkaitan dengan konsultasi dan intervensi untuk anak-anak, remaja, dan keluarga mereka, di komunitas Macau yang berubah dengan cepat. Kebutuhan dibahas dalam kerangka sistem, dan rekomendasi untuk pengembangan bidang dan kebutuhan untuk intervensi anak dan keluarga berbasis sekolah tambahan di wilayah tersebut dibahas (van Schalkwyk, 2013).

Berdasarkan hasil penelitian sebelumnya, menunjukkan bawa peran guru bimbingan dan konseling dari berbeagai Negara dalam menangani kasus bullying memiliki perbedaan. Seperti yang kita ketahui bahwa guru bimbingan konseling merupakan seorang konselor sekolah atau tenaga ahli yang mencurahkan seluruh waktunya pada layanan bimbingan kepada siswa dan menjadi konsuler bagi staf sekolah dan orang tua. Sehingga dibutuhkan manajemen bimbingan konseling.
Manajemen ini merupakan kegiatan yang diawali dengan melakukan perencanaan kegiatan bimbingan konseling, pengorganisasian aktivitas dan semua unsuk pendukung bimbingan konseling.

Menurut Thantawy manajemen bimbingan dan konseling merupakan upaya dengan berbagai metode untuk mendayagunakan secara optimal dan efektif semua komponen dari sumberdaya. Seperti yang diketahui, menangani bullying membutuhkan manajemen bimbingan dan konseling agar dapat meminimalisisr sikap tersebut secara efektif dan efisien.

\section{Manajemen Bimbingan dan}

Konseling ini dapat diwujudkan dengan memberikan layanan klasikal, individual, informasi, individual dan kelompok serta tindakan prevented kuratif. Karena dampak perilaku bullying berdampak pada korban seperti bersalah, terlibat perkelahian, tidak disiplin, kurang berempati dan mudah marah. Untuk itu, langkah-langkah yang dilakukan manajemen bimbingan dan konseling dalam mengatasi perilaku tersebut yaitu mengidentifikasi masalah, memberikan layanan bimbingan dan konseling, mengadakan kegiatan ekstrakurikuler dan melakukan pengawasan.

Diperlukan pengontrolan dalam pelaksanaan manajemen bimbingan dan 
konseling.Sehingga dapat diketahui, apakah pelaksanaan program sudah sesuai dengan perencanaan yang telah dibuat di awal semester? Perlu Evaluasi dan Supervisi dalam pelaksanaan program yang sudah dijalankan sehingga bisa diperbaiki disemester berikutnya.

\section{PENUTUP}

Penelitian ini menunjukkan bahwa masing-masing negara memiliki keunikan tersendiri dalam menyelesaikan masalah bullying. Dalam menghadapi kasus bullying setiap negara memiliki prosesnya sendiri.Setiap Sekolah memiliki manajemen bimbingan dan konseling sendiri didalam menangani kasus-kasus yang terjadi.Hendaknya memasukan Program Bimbingan Kelompok,Konseling kelompok maupun Individu dalam salah satu Program dalam Manajemen Bimbingan dan Konseling sebagai salah satu bentuk solusi dalam mengantisipasi terjadinya kekerasan didalam sekolah.Dan untuk penindasan yang banyak terjadi di Indonesia yang berbeda dengan di Afrika Selatan. Ini karena perbedaan budaya dan karakteristik masyarakat.

Dalam proses manajemen bimbingan dan konseling sekolah juga harus update dengan kondisi-kondisi didalam dunia pendidikan,sehingga bisa mengatur program disekolah sesuai kebutuhan sekarang dan yang akan datang.
DAFTAR PUSTAKA

Anis Widyawati. 2012. Preventif Terjadinya Tindak Pidana Kekerasan. Jurusan Ilmu Hukum Fak Hukum Negeri Semarang, 1-6.

Arofa, I. Z., Hudaniah, \& Zulfiana, U. 2018. Pengaruh Perilaku Bullying terhadap Empati Ditinjau dari Tipe Sekolah. Jurnal Ilmu Psikologi Terapan, 06(01), 74-92.

Bibou-Nakou, I., Asimopoulos, C., Hatzipemou, T., Soumaki, E., \& Tsiantis, J. 2014. Bullying in Greek secondary schools: prevalence and profile of bullying practices. International Journal of Mental Health Promotion, 16(1), 3-18. https://doi.org/10.1080/14623730.20 13.857824

Chireshe, R. 2017. School Counsellors' and Students' Perceptions of the Benefits of School Guidance and Counselling Services in Zimbabwean Secondary Schools. Journal of Social Sciences, 29(2), 101-108. https://doi.org/10.1080/09718923.20 11.11892960

Cowie, H., \& Colliety, P. 2016. Who Cares About The Bullies? Pastoral Care in Education, 34(1), 24-33. https://doi.org/10.1080/02643944.20 15.1119880

Djuwita, R. 2006. Kekerasan Tersembunyi Di Sekolah: AspekAspek Psikososial Dari BullyingVictims: A Comparison of Psychosocial and Behavioral Characteristics. Journal of Pediatric Psychology.

Dulmus, C. N., Sowers, K. M., \& Theriot, M. T. 2006. Prevalence and Bullying Experiences Of Victims And Victims Who Become Bullies (Bully- 
Victims) At Rural Schools. Victims and Offenders, 1(1), 15-31. https://doi.org/10.1080/15564880500 498945

Geldard, K. 2012 Konseling Remaja: Intervensi Praktis Bagi Remaja Berisiko. Yogyakarta: Pustaka Pelajar.

Gibson, R. L., \& Mitchell, M. H. 2011. Bimbingan dan Konseling. Yogyakarta: Pustaka Pelajar.

Hearne, L., \& Galvin, J. 2015. The Role Of The Regular Teacher In A Whole School Approach To Guidance Counselling in Ireland. British Journal of Guidance and Counselling, 43(2), 229-240. https://doi.org/10.1080/03069885.20 14.952622

Hughes, P. 1985. Guidance and Counselling in Schools. British Journal of Guidance \& Counselling, 13(1), $11-21$. https://doi.org/10.1080/03069888508 253787

Kettunen, J., \& Tynjälä, P. 2018. Applying Phenomenography In Guidance And Counselling Research. British Journal of Guidance and Counselling, 46(1), 1-11. https://doi.org/10.1080/03069885.20 17.1285006

Lam, S. K. Y., \& Hui, E. K. P. 2010. Factors Affecting The Involvement Of Teachers In Guidance And Counselling As A Whole-School Approach. British Journal of Guidance and Counselling, 38(2), 219-234.

https://doi.org/10.1080/03069881003 674962

Mohd Daud, N. A., \& Bond, T. 2013. Cultural Values And Attitudes
Towards Guidance And Counselling Services In One Secondary School in Malaysia: the role of a school cultural system. British Journal of Guidance and Counselling, 41(5), 544-558.

https://doi.org/10.1080/03069885.20 13.773957

Moore, M. O. 2012. Pastoral Care in Education: An International Journal of Personal, Cyber-bullying: The Situation in Ireland Cyber-bullying: the situation in Ireland. Pastoral Care in Education: An International Journal of Personal, Social and Emotional Development, (October), 37-41.

Muribwathoho, H. N., \& Shumba, A. 2006. Guidance and Counseling Services in South African Schools: Issues and Challenges. Journal of Psychology in Africa, 16(1), 123126.

https://doi.org/10.1080/14330237.20 06.10820112

O'Brien, N., Munn-Giddings, C., \& Moules, T. 2018. The Repercussions Of Reporting Bullying: Some Experiences Of Students At An Independent Secondary School. Pastoral Care in Education, 36(1), 29-43.

https://doi.org/10.1080/02643944.20 17.1422004

Özmen, S., Eren, H., \& Tezer, M. 2016. Elementary School Counseling Services Assessment: Students' opinion. Anthropologist, 25(3), 268277.

https://doi.org/10.1080/09720073.20 16.11892116

Povilaitis, R., \& Bulotaite, L. 2014. Prevention of bullying in Lithuania. International Journal of Mental Health Promotion, 16(1), 28-41. 
https://doi.org/10.1080/14623730.20

13.857826

Power-Elliott, M., \& Harris, G. E. 2012. Guidance Counsellor Strategies For Handling Bullying. British Journal of Guidance and Counselling, 40(1), 83-98.

https://doi.org/10.1080/03069885.20 11.646947

Van Schalkwyk, G. J. (2013). SchoolBased Counselling and Psychological Services in Macao. International Journal of School and Educational Psychology, 1(3), 207-216. https://doi.org/10.1080/21683603.20 13.822840 